\title{
What makes a fashion blogger on Instagram? The Romanian case study
}

\author{
Monica Ioana Lungeanu*, Lorenza Parisi**
}

*John Cabot University, Italy

** Link Campus University, Italy

\begin{abstract}
Fashion bloggers on Instagram can be considered as opinion leaders and trendsetters, 'authentic' content creators and collaborative personas. The article focuses on the Romanian fashion sphere case study to explore the ways in which fashion bloggers build their online personas. We conducted a content analysis of seven of the top Romanian fashion bloggers' accounts (by number of followers) focusing on their activity on posts and Stories over a period of two months (March-April 2017). The results present a classification of main posting categories for Instagram Feed posts, as well as trends and recurrences across Romanian fashion bloggers. The analysis reveals an intense collaboration and establishment of fashion partnerships through a continuous process of tagging one another, as well as attention to creating genuine, 'authentic' content that fosters intimacy with their followers.
\end{abstract}

Keywords: authenticity, fashion blogger, fashion partnership, influencer, Instagram, Romanian fashion sphere

\section{Introducing Instagram fashion bloggers}

Due to the digitalization of life, the online realm provides a space for new forms of expression. The fashion sphere has particularly experienced a growth in terms of new positions and roles that social media has enabled (Laurell, 2016, p.520). One relevant example consists in fashion bloggers ${ }^{1}$, who are independent online personas constantly reflecting on their own style and product preferences, sharing them with their audience via a fashion blog that they constantly update, as well as maintaining a strong social media presence (Laurell, 2014, p.23). They are independent because they do not work for a company or for profit, at least initially, and their success is based on giving genuine advice and sharing their personal opinions about beauty products or the latest trends. Marwick defines fashion blogging as "an international subculture comprised primarily of young women who post photographs of themselves and their possessions, comment on clothes and fashion, and use self-branding techniques to promote themselves and their blogs" (2013, p.1). By self-branding techniques, we understand the activity of marketing oneself as a brand, establishing a prescribed image or impression in the mind of others about oneself; in this case accomplished through the usage of their 'Public Figure' Instagram profile². Fashion bloggers' Instagram activity shows their interest

\footnotetext{
${ }^{1}$ Blogs are usually introduced in the category of new media, as a means of categorization which differentiates traditional from digital channels (Rocamora, 2012, p.92). Drawing from Bolter's belief that "the Web is the remediation of print" (2001, p.42), fashion blogs can be analyzed as the remediation of print magazines.

${ }^{2}$ Setting an Instagram profile as 'Public Figure' means that the user can, like company pages and brands, access statistics about their online interactions, as well as be aware of which type of posting attracts more attention and likes.
} 
in using marketing strategies that commercial brands adopt on social media ${ }^{3}$. Indeed, their success is reached through an informal, but well-judged communication mix.

Following a marketing perspective, Instagram fashion bloggers act as opinion leaders who exert their influence by providing a form of interaction that the professional fashion world lacks, while also representing sources of inspiration for their followers ${ }^{4}$. On Instagram, the most popular users who are able to exert a major influence over other users are called 'influencers's. In terms of digital communication strategies, the power of word-of-mouth should not be underestimated as it is seen by some as more effective than any other form of planned messages (Wiedmann, Henning \& Langner, 2010, p.142). Indeed, in a digitalized world, a review or a personal endorsement is still more valued than a company's press releases and customer service, which means that personal fashion blogs hold a strong advantage. Furthermore, as Marwick points out, there are many benefits that come with being a fashion blogger: from invitations to fashion shows, to free clothes and brand collaborations; encouraging more women, since females are predominantly the ones running fashion blogs, to start their own blog $(2013, p .1)$. Success of a fashion blogger can also lead to collaborations and sponsorships of brands, but, even then, they will be expected to continue posting from an 'authentic' perspective by their followers (Marwick, 2013, p.4).

According to Statista (2017), out of the 15 most popular Instagram accounts in 2017, seven are fashionrelated companies (Nike, Victoria's Secret, Nike Football, H\&M, ZARA, Adidas, Louis Vuitton) engaging millions of fans and indicating users' undebatable interest in the fashion sphere's online presence. Since it was introduced in 2010, Instagram grew at an accelerated rate. According to Pew Research Center, Instagram users are mainly female ranging from $18-29$ years old (Greenwood, Perrin \& Duggan, 2016). As the second most popular social media network after Facebook - even if it is owned by Facebook itself Instagram represents a space for young adults to tell their stories in a flexible and functional way "like we've never seen before" (Shively, 2015). "Instagrammers" (Becker, 2016) tend to check the platform at least once a day, creating a demand for constant content (Greenwood et al., 2016). Users tend to also regularly interact with brands or other forms of official accounts if they are entertaining, report useful information, or offer the chance of seeing exclusive peeks and behind the scenes photos (Becker, 2016). Of course, entertaining or useful content is highly subjective to each user, but generally, at the global level, there are large trends which interest and attract a large pool of individuals. In the fashion world, the most noticeable ones are makeup tips, outfit of the day posts and even narrations of funny instances.

Historically, social media have emerged as places where users could express themselves for non-commercial gains, switching from the intimate activity of writing a diary to blogging (Laurell, 2016, p.524). Following this tradition, Instagrammers use the platform as a form of photo-journaling, artistically documenting their

\footnotetext{
${ }^{3}$ An example of this professional attitude is the "Instacamp", an event held in Bucharest, Romania on July the 13th, 2018 containing tips about the best strategies for building one's Instagram profile. Sanziana Negru, one of the Romanian fashion bloggers analyzed in this article, participated as a speaker, contributing to a discussion on 'authenticity' in the Instagram era. In fact, it is not uncommon for Romanian influencers to give talks regarding their social media presence. ${ }^{4}$ On several SNS such as Instagram and Twitter, each profile publicly displays its number of 'followers' (other profiles that want to receive updates about the respective profile) and 'following' (the profiles that make up the respective profile's news Feed of information). Each profile has their own news Feed made up from posts of the profiles they are 'following'. ${ }^{5}$ On Instagram, users do not have to follow back their followers. The comparison between the number of followers and followings shows the popularity of an account: accounts with high follower/following ratio are influencers and celebrities.
} 
life (Becker, 2016); and perhaps this is the reason why fashion bloggers maintain a personal touch to their work online, especially through their Instagram Stories ${ }^{6}$. Visual self-expressions also help Instagrammers portray who they are, discover new interests, follow role models and build communities around similar interests. Young adults use this social network site to follow the latest trends and as a source of inspiration (Becker, 2016). In this context, as Laurell $(2016$, p.522) notes, "influential fashion bloggers become opinion leaders" by telling their self-concerning fashion stories.

The first part of the article provides an overview of the fashion blogging phenomenon. Nowadays, Instagram can be considered one of the most important showcases for the fashion word, due to its mainly visual language. The article conducts a content analysis of seven of the top Instagram accounts of the Romanian fashion sphere (by number of followers). Blogs represent one of the earliest platforms available in the contemporary media landscape (Laurell, 2014, p.3). The first fashion blogs was created around 2003, but it was not until three years later that the first Romanian fashion blog appeared (Tomiuc \& Stan, 2015, p.165). The type of fashion bloggers we focused on was categorized by Tomiuc and Stan as "Content Centered" (p.169), meaning that the primary scope is not brand collaboration (though possible), but the interest in producing 'authentic' content and offering an undistorted personal view on fashion trends. By analyzing a homogeneous group of users, we deconstructed the traits they share (Salmons, 2016, p.107).

Though not the most famous or praised fashion sphere, Romania provides an interesting case study. Romania is a developing country, therefore fashion plays a significant role in publicly displaying the most popular global trends. Along the years, the Romanian fashion industry has broadened, gaining more international attention. Fashion holds a relevant mainstream media presence in Romania, with highly viewed shows: 'Next Top Model' and 'My Style Rocks'. The most predominant Romanian fashion item is by far 'La Blouse Roumaine' (the traditional Romanian blouse). Designers like Venera Arapu or Andreea Badala have collaborated with big names such as Alexander McQueen, announcing their promising careers. Indeed, nowadays Arapu has a well-established brand, selling her creations in Paris and New York, while Badala has started Murmur, a bold and ultrafeminine silhouettes vintage lingerie concept (Gheorghe, 2014). There are also designers like Manghiuc Ramona who take a more alternative approach to fashion, celebrating imperfections in a desire to be 'authentic', never aiming for perfection (Gheorghe, 2014). As we will see in the results section of the article, this professed 'authenticity' is also a component of Romanian Instagram fashion bloggers' activity.

\section{Background: Instagram fashion bloggers' characteristics}

The lack of a fashion-related subject degrees encourages the audience to regard fashion bloggers as regular people, outsiders of the fashion world, just like themselves. For this reason, they represent a valuable resource in connecting the professional fashion world with the consumers. Being a "good fashion blogger"

\footnotetext{
${ }^{6}$ The Story is a relatively new feature on Instagram, a short multimedia content (a video or an image) that vanishes after 24 hours, meaning less attention to framing and editing.
} 
(Marwick, 2013, p.4), one must prove that they have both individual and social capital (Bourdieu, 1980). As identified by Wiedmann et al., individual capital goes from demographics to personality traits, to fashion involvement to expertise and knowledge (2010, pp.145-147). An aspiring fashion blogger has more chances of success if they are female, young adults or teenagers and have regular posts, confirming their interest in the subject. Social capital is gained through three dimensions: "structural (e.g. network links), relational (e.g. trust) and cognitive (e.g. shared goals and shared paradigms)" (Nahapiet \& Ghoshal, 1998). This correlates with the idea of appearing 'authentic' and trustworthy as described by Marwick (2013, p.4), but also to hypertextual linkage proposed by Rocamora. Furthermore, social influence and sustained social relationships represent social capital, as explained by Wiedmann et al. (2010, p.142). Therefore, successful fashion bloggers are individuals who have relationships with others from the community, disclose intimate information about themselves and share their personal views on trends and products. Another social capital trait they require is empathy (Wiedmann et al., 2010, p.147), which can be translated into presumed genuine and friendly interactions with their followers.

Instagram fashion bloggers can be identified according to three main traits: 1) act as opinion leaders and trendsetters; 2) establish interactive and collaborative relationships with the audience and with other fashion bloggers; and 3) produce 'authentic' content to foster intimacy with the users.

\section{Opinion leaders and trendsetters}

Fashion bloggers can be considered contemporary opinion leaders, people who are considered knowledgeable and trustworthy by others, "creating a 'two-step' flow" interpersonal influence within trusted social networks (Katz \& Lazarsfeld, 1955). In other words, fashion bloggers pass down information about fashion trends filtered by their own judgment. In the marketing environment, opinion leaders are labelled as 'early adopters' or 'innovators', referring to those initial highly-informed consumers when a new product is released. Following the technology adoption curve, innovators familiarize themselves with the product, start spreading the word about their new purchase and as soon as enough positive reinforcement confirms the qualities of the product, other consumers will follow their example and buy it (Rogers, 1995, p.54). Ramos-Serrano \& Martínez-García argue that "opinion leaders exercise greater influence on people's opinions than mass media or those media which are controlled by the fashion industry" (2016, p.90). Indeed, fashion bloggers are perceived as outsiders of the official fashion sphere, as they do not hold any formal education in the domain, nor a job position. As Walsh calls it, "the expert paradigm" (Walsh, cited in Jenkins, 2006, p.52) is an appropriate way to describe fashion bloggers as independents who try to claim legitimacy in a field they do not have all the required knowledge to be part of. This also correlates to Carlson's view on the increasingly blurring boundary between journalism and non-journalism (2007, p.265). An individual who owns a professional camera is not automatically a photographer, while an internet connection and the possibility to create a free blog or social media profile do not make a journalist. It is through self-analysis and promotion that such individuals become trend setters and opinion leaders (Tomiuc \& Stan, 2015, p.166). 
Increasingly, the internet and social media represent a space which combines interpersonal communication with brand communication, leading to a need for bloggers (content creators) to use social media as a storytelling platform featuring their personal life to connect with other users (Ramos-Serrano \& MartinezGarcia, 2016, p.90). At the same time, being a fashion blogger can prove very profitable due to many free products, invitations to exclusive fashion events, as well as brand collaborations and sponsorships. Nonetheless, fashion bloggers regard commercial interests as potential, but not necessary (Marwick, 2013), which enables them to appear truthful in their choice of products to wear and endorse.

\section{Fashion bloggers as interactive and collaborative personas}

In web 2.0 (O'Reilly, 2005), social media sites and blogs are described as interconnected platforms where content can be modified by all users in a collaborative manner (Laurell, 2014, p.3). Fashion bloggers are frequent users of hypertextuality. Hypertext for Landow "denotes an information medium that links verbal and non-verbal information" (2006, p. 3). By joining different fragmented parts of text, sounds, and images, connected by links, hypertextuality enables users to escape the constraints of linear reading of media texts (Cerić, 2013, p.20). Hypertextuality also aids interactivity, understood as the option of choice (Cerić, 2013, p.19). Linking information is only the first step, providing the right environment, but users need to act upon it to be considered interactive. Fashion bloggers don't pass down this invitation, being very interactive.

On Instagram, 'mention"7 (or tagging) is known as the means of linking to profiles or keywords (hashtags). Following Instagram logic, acquiring 'mentions' boosts a user's profile, which can translate in gaining more attention and inherently more followers. Fashion bloggers use this tagging feature to attract brands' attention - and in turn to promote their products to potential customers (Tomiuc \& Stan, 2015, p.168). Tagging is also used as a way of encouraging one's followers to subscribe to their friends' accounts (Koughan \& Rushkoff, 2014).

Emerging digital technologies have led to an increasingly higher rate at which "fashion information is spread from various sources through multiple media outlets" (Laurell, 2016, p.523). In the current era of speed, trends come and go with almost no time in between: "more than any other media, fashion is transient, passing, already gone" (Rocamora, 2012, p.97). Keeping up with fashion movements becomes increasingly more difficult, resulting in fashion bloggers acting as intermediaries between customers and companies, directing their followers to the website of the brand they are wearing or talking about.

Fashion bloggers also require a certain status and visibility on the social media platform (Instagram), offered mainly by the number of followers, but also by the quality of their interactions. Wiedmann et al. notes that "the extent to which a social influencer can actually act as a source of influence is not only characterized by the grade of social integration but also by the strength of social relations" (2010, p.147). The strength of relations is achieved by fashion bloggers through collaborations with selected brands or other fashion

\footnotetext{
7 Through the use of '@' before their friend's account name.
} 
bloggers. The mentions they earn by associating with mainstream companies or popular users propel their visibility on Instagram (Schaefer, 2014, p.777).

Not being sociable or known in this world could send the wrong message to the audience: that they do not care enough or that they are not viewed as worthy by the rest of the community (Marwick, 2013, p.5). This could be a deal breaker for an aspiring fashion blogger. As we will see in detail, Romanian fashion bloggers often hang out together, go to trips, co-plan creative projects or 'mention' one another through their profile and Story posts during 'Instagram Live Stories'8.

\section{Fashion bloggers as 'Authentic' Content Producers}

Fashion bloggers differentiate themselves from professional mainstream fashion platforms through original and personal content they produce and share with their audiences (Bruns, 2005). According to critical theory, their activity is definitively conformist and contributes to feed the so-called "society of the spectacle" (Debord, 1967), a false reality based on mass media images, creating 'pseudo-needs' which are continuously manufactured and subsequently imposed on the consumers. The 'false needs' produce the spectacle via the media, and this spectacle, or series of appearances, becomes the reality of our everyday lives. When everything is reduced to appearances, real social issues created by the capitalist mode of production and its uneven distribution of wealth, such as class inequality or poverty, are concealed by the spectacle in order to protect the dominant order of power. As a result, a main recurrent problem is that fashion blog contents reinforce hierarchies of aesthetics, taste and knowledge (Pham, 20011. Similarly, most famous Romanian fashion bloggers follow the traditional fashion mold: "rich, thin, tall, heterosexual, and white" (Marwick, 2013 , p.1). Moreover, representing oneself online as a fashion persona takes place within a commercial context of branding and advertising practices. In the context of online representation, 'authenticity' is seen by Marwick as a way to differentiate fashion bloggers from one another, but also from other fashion platforms, such as magazines or corporate pages $(2013$, p.1).

While the critical theory offers an invaluable frame to interpret fashion bloggers as part of the consumer society, we also believe that fashion bloggers can play a crucial role in shaping the influential process, interpreting the corporate message by adding their personal touch. Within a spreadable media landscape (Jenkins, Ford \& Green, 2013) they act as cultural intermediaries between brands and consumers' needs. Indeed, through their social media activities, they contribute in establishing the cultural meaning of fashion products, taking possession and modifying the symbolic meanings they carry. Audiences can get suspicious if a blog is too perfect because of its high similarity to a corporate page. Official websites offer a constructed image for all their looks and models, making customers wonder if a 'real' woman could ever keep up with that. This represents an opportunity for fashion bloggers to show that they, as regular citizens, managed to find a way to be fashionable, demonstrating their trustworthiness (Marwick, 2013, p.5). An insincere aspect

\footnotetext{
${ }^{8} \mathrm{~A}$ mode of creating Story posts by recording oneself and allowing their followers to join and watch them in real time.
} 
of the Instagram profile page can cost the fashion blogger their audience's trust. The same can happen if they appear to be engaging with brands just for money, without genuinely endorsing the products they mention (Marwick, 2013, p.6).

Laurell $(2014$, p.16) explains how digital technologies have enabled a new form of value creation through co-creation and brand co-creation, involving both fashion bloggers and customers. In this new environment, fashion bloggers can draw on the type of power and influence historically attributed to firms, while the variety of points of interaction offers the opportunity for both value creation and extraction for customers (Laurell, 2014, p.16). As a result, interactions taking place on fashion bloggers' profiles produce a "common social world" (Arvidsson, 2006) that shapes the meanings of fashion trends and habits.

An 'authentic' fashion blogger has to relate intimate details about oneself to create the sense of a personal relationship with their audience, while using self-branding techniques to get attention and visibility (Marwick, 2013, p.2) as part of the growing practice of human social life commercialization (Laurell, 2014, p.21). Their posting activity reveals they are digital marketing savvy, adopting professional social media strategies to get a wider audience. Self-branding includes the genre of fashion photography, with movement poses on streets, leaning on external walls, or while walking away from the camera (Rocamora, 2012, pp.101-102). Fashion photography proves that fashion can exist in real life, not only in magazines, and inherently that ordinary people can follow trends and become fashionable.

By publicizing their lives, fashion bloggers offer an immediate gratification to their followers (Rocamora, 2012, p.102). Moreover, the ability of followers to interact with fashion bloggers represents a main aspect that differentiates them from companies: they help establish connectedness and show that the fashion blogger is a 'real' person who cares about others (Marwick, 2013, p.5). The immediate nature of content posted by fashion bloggers "favors informality, direct conversational modes of address, and a certain assumption of intimacy (sometimes even of ironic complicity) with the audience" (Tomlinson, 2007, p.100). Fashion bloggers are equivalent to acquaintances, holding no symbolic barriers to signal them as mediators of a corporate message. Thus, they can exert influence because they are perceived as member of specific communities, primus inter pares (first among equals). According to Marwick, audiences value honest and personal thoughts, providing useful information to 'real' women, answering their questions and meeting their needs (2013, p.7).

\section{Method}

To describe how fashion bloggers on Instagram reach and maintain their role of 1) opinion leaders and trendsetters, 2) 'authentic' content creators and 3) collaborative personas, we carried out a content analysis of the top seven Romanian fashion bloggers' accounts (by number of followers) focusing on their activity on Feeds and Stories (as two distinctive channels), over a period of two months (March-April 2017). The Romanian fashion sphere offers an interesting case study to observe how fashion bloggers create, remix and spread information on Instagram. As mentioned above, the Romanian fashion sphere is predominantly 
expressed in Romanian language, although bloggers are very connected with global trends: they contribute to spread international fashion trends to the Romanian audience under a Western influence, thus acting as intermediaries (i.e. they connect international trends to the local context).

Fashion bloggers need to incorporate several characteristics in order to be worthy of attention and recognition from an audience. The selected unit of analysis follows this constructed guideline. They are all female $^{9}$, around 25 years old, have over $12 \mathrm{k}^{10}$ Instagram followers (as of March 2017), share a lot of intimate details about their lives and make regular postings regarding fashion and beauty (individual capital). At the same time, their social capital becomes visible through their interactions with their followers either through comments or verbal responses during 'Instagram Live Story' sessions, collaborations with other fashion bloggers and creation of personal fashion projects as alternative expressions to their brand endorsement contracts. Since fashion blogging is nowadays a full time job, bloggers have the chance to make money (Marwick, 2013, p.5) by signing endorsement contracts with brands, doing advertising campaigns and assuring a specific number of posts in which they instigate their audience to purchase the endorsed brand's product or service.

In March 2017, we identified a group of the 13 most popular Romanian fashion bloggers by number of followers (Table 1). These women refer to themselves as fashion bloggers (some also as beauty and/or lifestyle bloggers).

Table 1: Identified Fashion bloggers and their evolution over two months of observation

\begin{tabular}{|c|c|c|c|c|}
\hline Ranking (March) & $\begin{array}{c}\text { Followers } \\
\text { (March) }\end{array}$ & Fashion Blogger & $\begin{array}{c}\text { Followers } \\
\text { (April) }\end{array}$ & Ranking (April) \\
\hline 1 & $262 \mathrm{k}$ & Alina Ceusan & $288 \mathrm{k}$ & 1 \\
\hline 2 & $142 \mathrm{k}$ & Ioana Grama & $158 \mathrm{k}$ & 2 \\
\hline 3 & $131 \mathrm{k}$ & Carmen Grebenisan & $147 \mathrm{k}$ & 3 \\
\hline 4 & $95 \mathrm{k}$ & Ana Morodan & $108 \mathrm{k}$ & 4 \\
\hline 5 & $94 \mathrm{k}$ & Diana Enciu & $101 \mathrm{k}$ & 6 \\
\hline 6 & $81,4 \mathrm{k}$ & Alina Tanase & $89,7 \mathrm{k}$ & 9 \\
\hline 7 & $88,5 \mathrm{k}$ & Chisiu Ioana-Carmen & $95,5 \mathrm{k}$ & 8 \\
\hline 8 & $79,5 \mathrm{k}$ & Sandra Bendre & $88,7 \mathrm{k}$ & 10 \\
\hline 9 & $70,9 \mathrm{k}$ & Sanziana Negru & $104 \mathrm{k}$ & 5 \\
\hline 10 & $56,6 \mathrm{k}$ & Sinziana Maria Iacob & $64,6 \mathrm{k}$ & 11 \\
\hline
\end{tabular}

\footnotetext{
${ }^{9}$ We chose to analyze only women given that that females dominate in number the Romanian fashion blogosphere (Tomiuc \& Stan, 2015, p.166).

${ }^{10}$ The number of followers in the tables are expressed in k, meaning thousand - so $12 \mathrm{k}$ refers to 12000 .
} 


\begin{tabular}{|c|c|c|c|c|}
\hline 11 & $45,5 \mathrm{k}$ & Madalina Merca & $100 \mathrm{k}$ & 7 \\
\hline 12 & $32,5 \mathrm{k}$ & Diana Rogo & $36,7 \mathrm{k}$ & 12 \\
\hline 13 & $12,8 \mathrm{k}$ & Stefana Suciu & $25,5 \mathrm{k}$ & 13 \\
\hline
\end{tabular}

The research initially focuses on the above mentioned 13 Romanian fashion bloggers. As Table 1 shows, over the two months of observation (March and April 2017) there has been a rise in the fashion blogger's Instagram followers list. We decided to analyze as case studies the most interesting profiles in the ranking according to April 2017 ${ }^{11}$. The leading three bloggers: Alina Ceusan (288k), Ioana Grama (158k) and Carmen Grebenisan (147k), as well as Enciu and Tanase, who constitute in a fashion duo that dropped in rankings, from the 5th and 6th positions in March to the 6th and 9th at the end of April. Then we included two cases performing the largest increase of followers: $54.5 \mathrm{k}$ new followers gained by Madalina Merca, who skipped four ranking positions from $11^{\text {th }}$ to $7^{\text {th }}$, and $33.1 \mathrm{k}$ new followers for Sanziana Negru, who advanced from the $9^{\text {th }}$ to the $5^{\text {th }}$ ranking position. Those 7 Romanian fashion bloggers (in grey color in Table 1) constitute our selected corpus.

Following a qualitative content analysis research method (Salmons, 2016, p.7) and like Ramos-Serrano \& Martínez-García's approach (2016), we decided to focus on extant data, understood as the analysis of images, videos and texts posted by fashion bloggers on their Instagram pages. We believe content analysis is the appropriate method to explore the visual self-expression culture fashion bloggers portray. As Table 2 shows, over the period of investigation, the seven bloggers posted a total of 1067 images (555 photos posted in March and 512 in April).

\footnotetext{
${ }^{11}$ After we carried out the content analysis, most of the fashion bloggers we investigated got a nomination for "Digital Divas", the above mentioned Romanian fashion awards ceremony, confirming that the selected bloggers are amongst the most prominent figures in the Romanian fashion sphere.
} 
Table 2: Overview of daily number of posts of the 7 selected fashion bloggers over the period of analysis by April's ranking in terms of followers.

\begin{tabular}{|c|c|c|c|}
\hline Fashion Blogger & March (Total) & April (Total) & TOTAL (both months) \\
\hline Alina Ceusan & 149 & 122 & 271 \\
\hline Ioana Grama & 53 & 64 & 117 \\
\hline Carmen Grebenisan & 100 & 86 & 186 \\
\hline Sanziana Negru & 102 & 81 & 183 \\
\hline Diana Enciu & 49 & 43 & 92 \\
\hline Madalina Merca & 26 & 42 & 68 \\
\hline Alina Tanase & 76 & 74 & 150 \\
\hline TOTAL (all bloggers) & $\mathbf{5 5 5}$ & $\mathbf{5 1 2}$ & $\mathbf{1 0 6 7}$ \\
\hline AVERAGE/DAY & 4.47 & 4.26 & 4.37 \\
\hline
\end{tabular}

Our content analysis classified the 1067 total number of Instagram Feed posts into categories established according to the classification of the activity of the most prevailing fashion blogger, Alina Ceusan. As the leading Romanian Instagram fashion blogger, recognized through her "Digital Divas" awards ${ }^{12}$ and with almost twice as many followers than her competition in March 2017, Ceusan represents a setting example for the rest of the fashion blogosphere. Ceusan is also in tune with global fashion trends, constituting in an intermediary between the international and Romanian fashion world. Considering this, we decided to establish the postings categories based on Ceusan's online activity. This decision to infer categories looking at the leading Romanian fashion blogger fits with the Instagram social architecture: a social network site establishing asymmetric relationships between several ordinary users and a few influencers. This means that trends are set by a few fashion bloggers - the top opinion leaders acting as 'hubs', which are then diffused towards other 'minor' fashion bloggers.

We started with analyzing Ceusan's Feed posts and then, during the analysis, we discussed the coding. Then, during the analysis, we noticed that other fashion bloggers made posts filling the same or less categories than Ceusan. Our final consensual scheme included 11 categories for annotation. The categories describe the actual visual cues (objects, places, people) presented in each posting plus text and hashtag. The two things (visual cues and text) can't be analyzed as separate given that the text conveys valuable information and contextualizes the message. Categories are the following (in alphabetical order): Behind the scenes; Brand Promotion; Fashion Partner; Food \& Drinks; Gym; Group Picture Posts Interior Design; Other; Outfit; Selfie and Vlogging Teaser.

\footnotetext{
12 "Digital Divas" is Romania's main fashion awards ceremony, recognizing and celebrating fashion bloggers' activity. The most relevant category in relation to our research was the "Best Instagram Account (In Fashion \& Beauty)", a category which was won three years in a row (2016-2018) by Alina Ceusan.
} 
Categories are not mutually exclusive, meaning that a photo may feature different elements which could place it under two or three categories. As a result, postings' classification was subjective to our own interpretation. For instance, Image 1 combines Fashion Partner with Gym, Brand Promotion and Selfie categories. The final classification decision was driven by observing the picture's caption (written by the blogger herself). In this case, after a discussion, Image 1 was placed under Gym due to its caption "Burst of electricity", which also includes the hashtags (\#) gym and fitness and the mention (@) of the actual gym where they were. The example shows we analyzed a post as a whole (image/video + text with hashtags). The two things (visual and textual content) can't be analyzed as separate, given that the linguistic message conveys valuable information and guides the interpretation of the image (Barthes, 1964).

Image 1: published on Instagram by Carmen Grebenisan on April 11, 2017
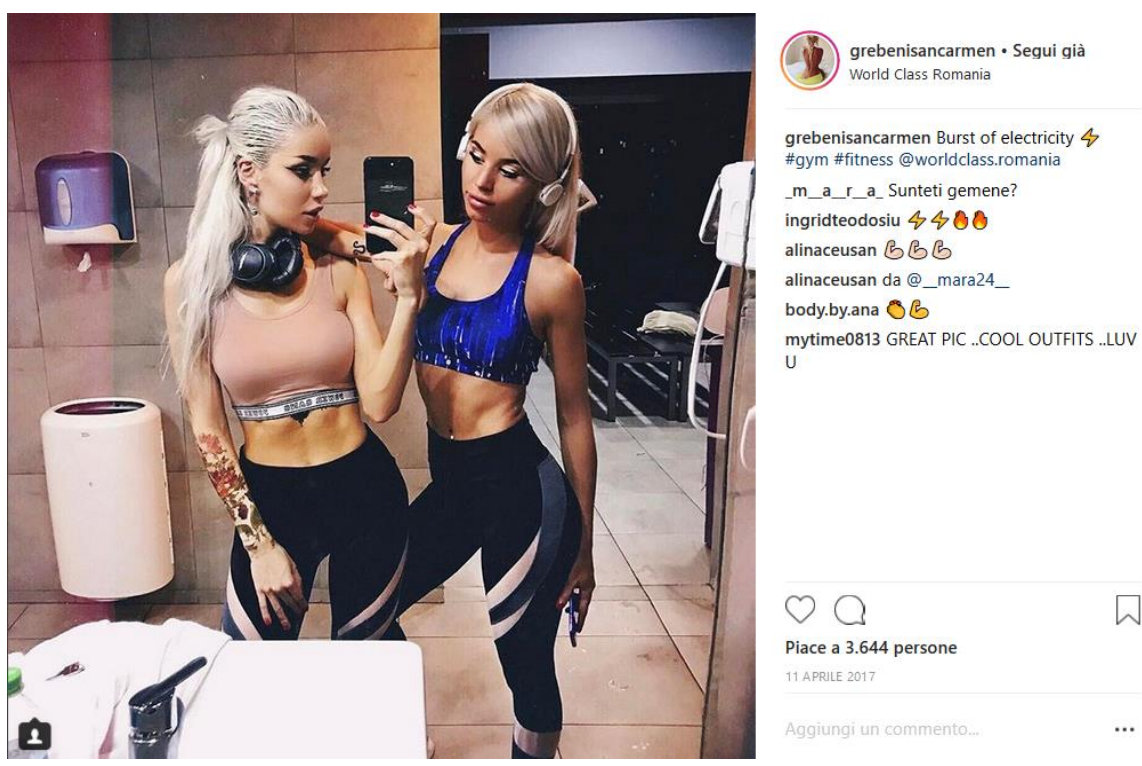

Lastly, the observation analysis of Instagram Story posts followed a similar process and we discussed the coding for video annotation. In this way, Story posts were classified in 4 categories (in alphabetical order): Acting Silly, Behind the Scenes, Edited Photos and Vlogging. Similar to the Feed posts, Behind the Scenes and Vlogging categories present the same type of content (but generally in video format, as opposed to the favorized picture format for Feed posts). Moreover, the Story annotation required the addition of two new categories: Acting Silly and Edited Photos, confirming the difference, in terms of content, between Feed and Story post. Acting Silly describes Stories in which bloggers fool around, laugh and nag each other. Meanwhile, the Edited Photos category represents a combination of Outfit and Brand Promotion (categories) Feed posts, consisting in professionally-looking Story posts. The Acting Silly Story category emphasizes Wiedmann et al. (2010)'s arguments regarding social capital by forming a social relationship between the bloggers and their followers, while the 'authenticity' of this content reinforces the bloggers' ordinariness, as part of the growing practice of human social life commercialization (Laurell, 2014, p.21). The following 
analysis is based on Instagram Feed and Stories posts of the seven selected fashion bloggers. As Moore (2016) explains, "Instagram content can be delivered episodically through Stories or more permanently through the Feed". The two main types of Instagram posts - on the Feed or in the Story - support different content-types and come with very different user behaviors. An important mention regarding Feed posts is that each post may contain different visual formats: image, text image ${ }^{13}$ or video.

\section{Results and Discussion}

The results section analyzes frequency and content categories regarding Instagram Feed posts of the selected fashion bloggers' Feeds; then it describes similarities, recurrences and visual themes in respect to Instagram Story posts. Regarding Instagram Story posts, the bloggers had an average of 20 Story posts/day. Being a fashion blogger requires constant, every day social media activity. Indeed, our research shows that there are only some days when the bloggers didn't post (39 days in total for all bloggers). The average number of Feed posts/day is 4.37, with the busiest days representing 10 posts made by Ceusan (March 1st, April 6th) and Grebenisan (April 3rd). However, the number of postings alone does not determine a user's ranking. For instance, Grama has less postings than Grebenisan but holds the second ranking place.

\section{Content Analysis of Instagram Feed Posts}

As shown by Table 3, the four predominant categories were Outfit, Brand Promotion, Selfie and Fashion Partner (with total monthly averages of $25.99,9.49,8.35$ and 7.28 posts) ${ }^{14}$, while the least favorite categories were Vlogging Teaser, Behind the Scenes and Gym (with the monthly posting averages of 2.64, 1.42 and 0.92 ). Firstly, will we briefly describe and comment categories, and then we will add some more considerations about the most relevant categories.

Table 3: Overview of average monthly number of posts/category over the period of analysis by popularity

\begin{tabular}{|c|c|}
\hline Category & Total posts average/month \\
\hline Outfit & 25.99 \\
\hline Brand Promotion & 9.49 \\
\hline Selfie & 8.35 \\
\hline Fashion Partner & 7.28 \\
\hline
\end{tabular}

\footnotetext{
${ }^{13}$ Instagram does not allow the posting of plain text, but a way to go around it is to create an image with the text against a background.

${ }^{14}$ To be noted that Other has the fourth biggest monthly average (with 8.2 posts), but it is not as relevant since it is composed by numerous types of postings, mainly landscapes, quotes and portrait drawings sent by followers.
} 


\begin{tabular}{|c|c|}
\hline Food \& Drinks & 4.64 \\
\hline Interior Design & 3.78 \\
\hline Group Picture Posts & 3.42 \\
\hline Vlogging Teaser & 2.64 \\
\hline Behind the Scenes & 1.42 \\
\hline Gym & 0.92 \\
\hline Other & 8.2 \\
\hline
\end{tabular}

Selfies have undergone a fast process of transformation, starting as a shameful activity associated to narcissism (Baym \& Senft, 2015, pp.1589-1590) to becoming a characteristic of today's visual culture (Peraica, 2017). As visual self-presentations, selfies hold insightful cultural connotations about the digital modern age. Baym and Senft find selfies as an opportunity for users to reflect on their identity, as both architects of social media essence and as followers of social trends (2015, p.1595). Therefore, fashion bloggers' selfies have social capital, reinforcing a widespread social media trend while also aiding the construction of their online persona. Even in the absence of a photographer, Instagram fashion bloggers can assure content for their followers through selfies; for instance, with the help of a long mirror, they can easily share their \#OOTD (outfit of the day).

Other relevant categories were Food \& Drinks (average of 4.64 posts/month), Gym (average of 0.92 posts/month) and Interior Design (average of 3.78 posts/month) emphasizing contemporary social trends and cultural values. By engaging with these social trends, fashion bloggers act as 'early adopters' or opinion leaders, passing down the latest information to their followers (Rogers, 1995). The Gym category correlates to the current global interest in healthy living. This relatively new industry has grown at an accelerated rate and nowadays the best fitness and healthy lifestyle blogs are being widely recognized and acclaimed, setting an example for bloggers in all other areas. Fashion and lifestyle blogging often come together, meaning that Instagram fashion bloggers engage with health-related subjects too. This can be seen by some of the bloggers' interest in sharing gym posts, as well as talking about various physical activities, or healthy meals. Food \& Drinks is a category linked not only to the healthy lifestyle trend, but also to the larger 'foodie' ${ }^{15}$ phenomenon. Understood as consumer behavior, social interest has shifted from physical products to experiences, as consumers are now willing to spend more money on food when seen as an experience, especially for health benefits (Sarasohn-Kahn, 2016).

As a final component of global social media trends, Interior Design is a relatively popular category amongst Romanian fashion bloggers, being mainly linked to lifestyle blogging, while also including elements of designs and patterns that could otherwise be associated with fashion design. Image 2 portrays Grebenisan's approach to engaging with these widespread trends.

\footnotetext{
${ }^{15} \mathrm{~A}$ person who loves food and is very interested in several types of food.
} 
Image 2: all three photos published on Instagram by Carmen Grebenisan on April 3rd, 2017; categorized from left as - Other (landscape), Interior Design, Food \& Drinks
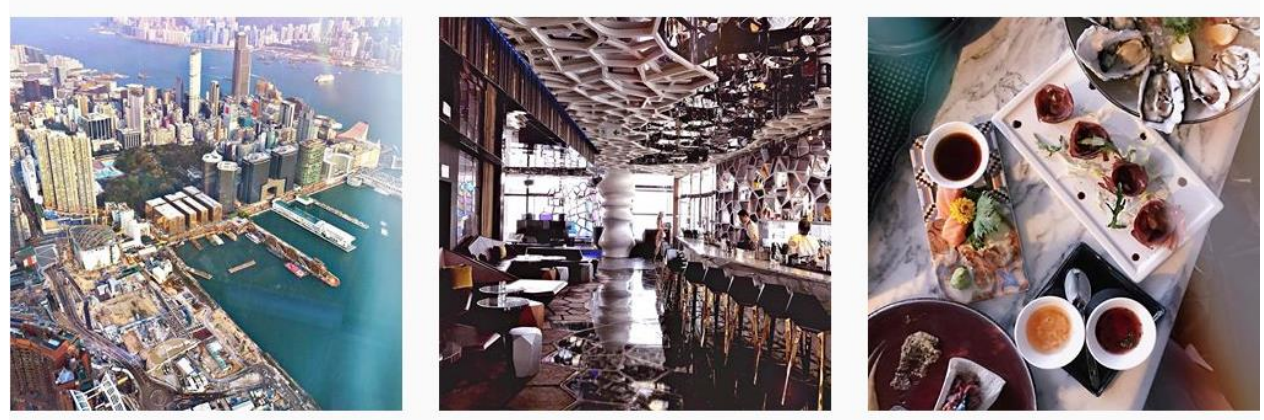

Behind the Scenes represents a category directly connected with the idea of 'authentic' content creation. The bloggers show followers their backstage (Goffman, 1959), such as exclusive peaks from photo shoots or pre-product release events, attempting to establish an informal and more intimate connection with their audience while also reinforcing the advantages they get from following them. As the analysis of Instagram Story posts will show, fashion bloggers use 'Live Stories', 24-hours lasting content, to disclose the Instagrammers' backstage and to chat in almost real time through comments. In this way, the fashion bloggers exploit the Internet grass-root culture (based on peer to peer interactions and user-generated content) to spread mainstream fashion trends.

Within a commercial context of branding and advertising practices, the category of Vlogging Teaser only contains video postings which are aimed as advertisement for the vlogging episode to come. While the actual vlogging episode could not be uploaded on Instagram due to a shortage of space, fashion bloggers create short teasers trying to attract their Instagram followers on their YouTube page. Furthermore, not all the bloggers pursue vlogging, but the ones that do (Ceusan, Grebenisan, Grama, Merca, Negru) are amongst the ones that maintained or advanced in their ranking, reinforcing the importance of having an online presence on various social network sites. Meanwhile, the Enciu-Tanase duo lacking a strong YouTube presence, also lost their ranking positions.

Since the bloggers' main online purpose is to engage with fashion-related topics, it does not come as a surprise that they favor sharing Outfit and Fashion Partner posts. Moreover, Brand Promotion (understood as instances when the blogger emphasizes the qualities of a specific product and prompts their followers to buy it) is very popular, calling attention to the importance of fashion bloggers' component of brands endorsement.

Outfit was, especially in March, Romanian fashion bloggers' favorite category, with 45 such posts made by Grebenisan, followed by 44 posts by Ceusan and 36 posts by Negru. When sharing a photo of an outfit, the fashion blogger generally tags the brands they are wearing directly on the photo. Sometimes, they urge their followers to follow a link to their blog to read details about their 'Latest Look' (an alternative to social 
media's \#OOTD). Moreover, as it can be seen in Image 3, outfit posts feature carefully framed and edited photos, presenting the fashion bloggers as glamorous models; which is consistent with Rocamora's argument on how fashion bloggers assimilated fashion photography expressed through poses and movement skills (2012, pp.101-102).

Image 3: from left- published on Instagram by Sanziana Negru on April 14th, 2017, Alina Ceusan on April 8th, 2017 and Madalina Merca on April 1st, 2017

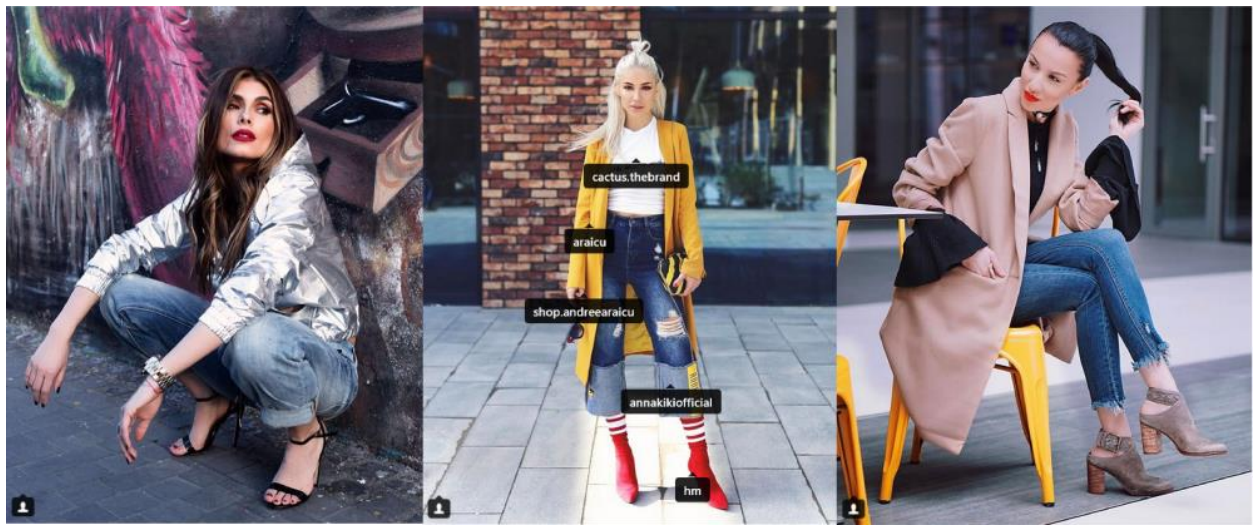

An important aspect of a Romanian fashion blogger is their active effort towards community building. Fashion bloggers have a lot of collaborations, coming up with exciting projects and fascinating cophotoshoots on a regular basis. Our findings are consistent with Rocamora's argument that through tagging (mentions and hashtags in the case of Instagram), fashion bloggers link potential consumers with the brands they endorse. When posting a picture on their profile, the fashion blogger will almost indubitably tag the brand they are wearing either using the '@' shortcut (mention feature) in the description or by directly tagging the brand's Instagram profile in the photo. Sometimes, they will also include hashtags as a further promotion of the brand. For instance, in Image 4, Grebenisan is inviting her followers to join the opening fashion show of Tezyo shoes in Cluj. The post's description combines the English language with Romanian (the so-called 'romgleza', a combination of Romanian and English, the new language of young Romanians under a Western influence) in such a way that both Romanian speakers as well as international individuals can understand the promotion strategy. Furthermore, 'romgleza' is often the result of the English and Romanian comments on the bloggers' posts. 
Image 4: posted on Instagram by Carmen Grebenisan on April 25th, 2017
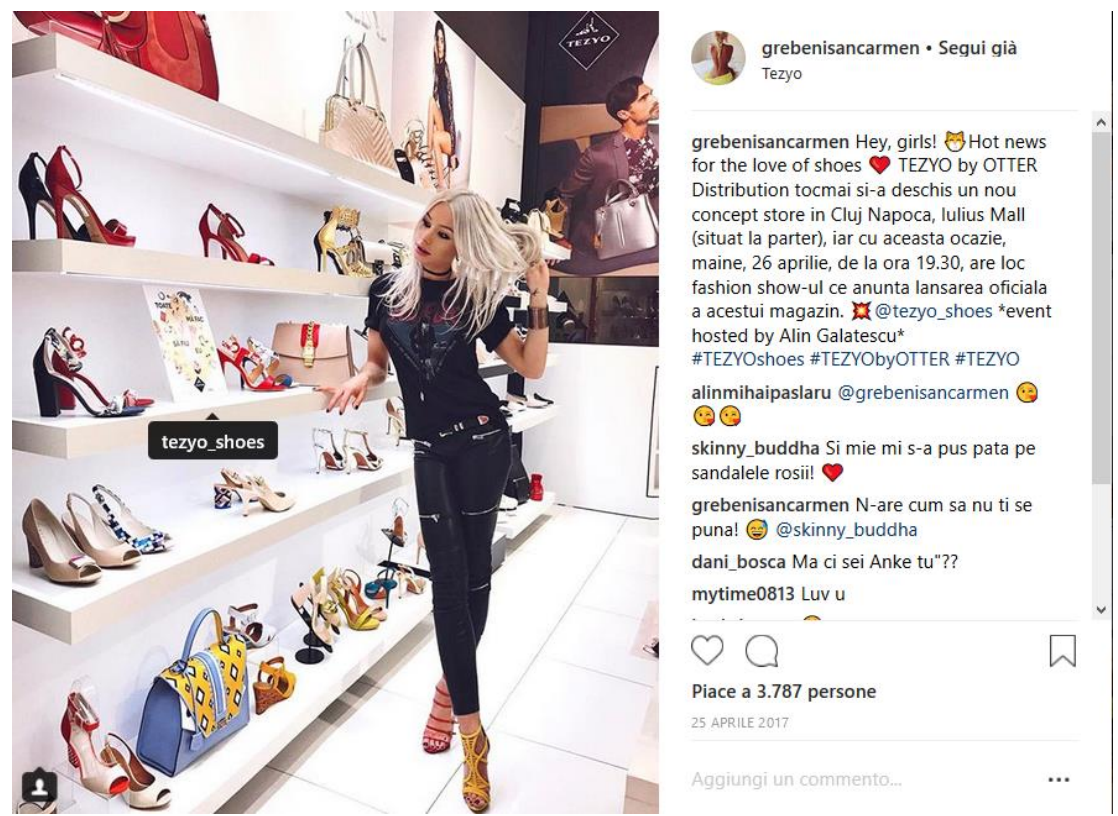

As the second most popular category of postings of Romanian fashion bloggers, Brand Promotion posts feature photos of the influencers in fashionable clothes, shoes or accessories referring to the specific brand they are wearing. Whether their outfit is made out of various brands (Ceusan, Grebenisan, Enciu, Tanase) or entirely provided by the same company (Grama, by Levis Jeans), fashion bloggers almost always tag the brands they are wearing. Moreover, each fashion blogger has preferred brands and brand collaborations, leading to each blogger's regular tagging of two or three main companies (for example, Ceusan often taggs Motivi, Flash Tattoos and Nympha Clothing, while Grama Stradivarius, Diva Charm, TEZYO Shoes and Desperados).

Reinforcing the identified characteristic of Romanian fashion bloggers as collaborative, another finding regards their brand interactions. In the case of a campaign launched by TEZYO Shoes, Grebenisan, Grama, Merca and Chisiu worked together in promoting the opening of a new store location, while Tommy Hilfiger and Cosmopolitan Magazine's campaign featured the collaboration of four prominent Romanian fashion figures (Grebenisan, Chisiu, Negru and Ceusan). Image 5 represents an example of a picture from the campaign posted by Ceusan, who also provides some information about it in the caption. 


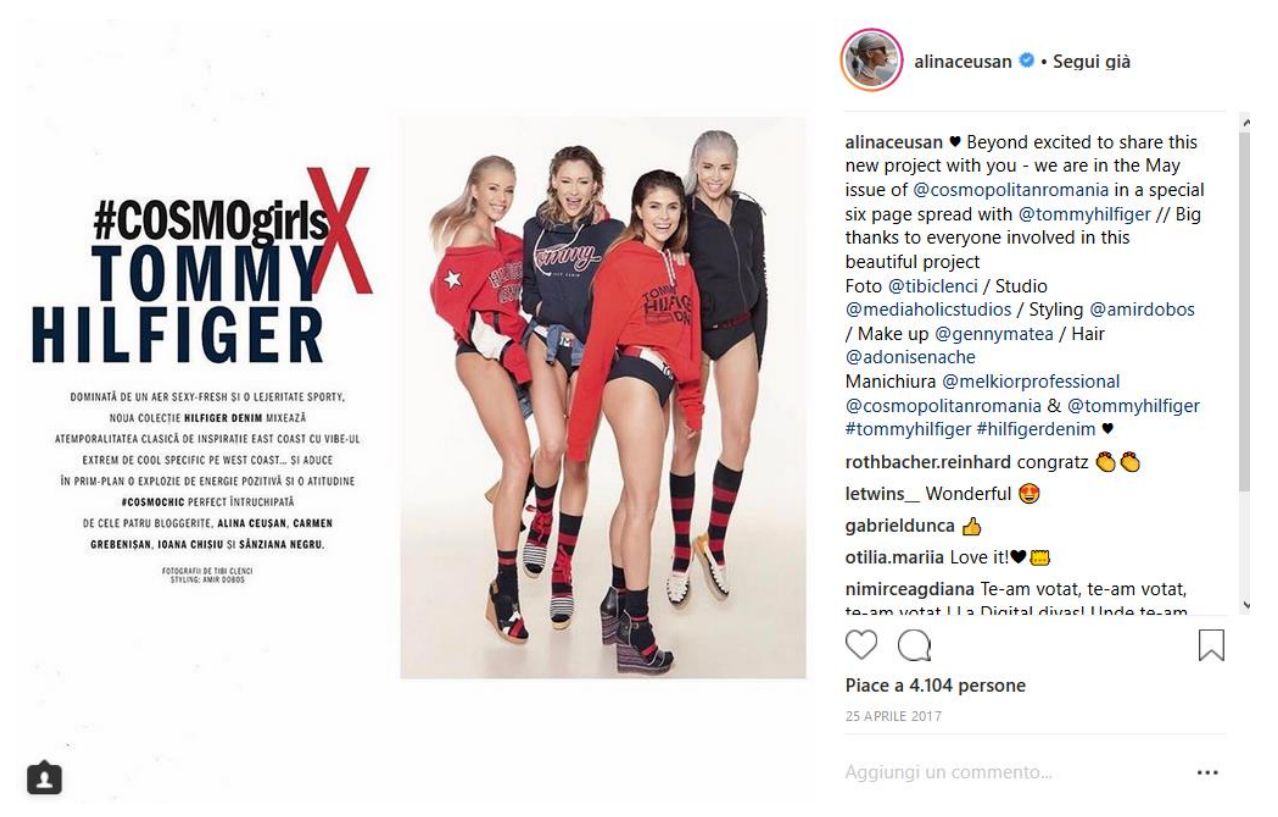

Collaborating with brands is an important part of a fashion blogger's online activity, but it is not the only type of collaboration they engage in. Some of the bloggers have established a long-lasting horizontal partnership with another fashion blogger (Fashion Partner), which translates into a considerable number of postings together (average of 7.28 posts/month), creative projects or even shared business ventures. This phenomenon is mainly followed by the Enciu-Tanase and Ceusan-Grebenisan couples, while also at a lower amplitude by Grama-Iacob (who are co-promoting some of the same brands) and Grama-Bendre (on their trip to Vienna in March 2017). Enciu-Tanase is an outspokenly established fashion duo, with a co-owned fashion blog called 'Fashion Muses'. The partnership is reinforced by the choice of their Instagram nicknames: 'fabmuse_diana' and 'fabmuse_alina'. They also designed a shoes collection together. Similarly, Ceusan-Grebenisan have recently opened a swimsuits online shop, entitled INFSD Swimwear, which they have been promoting with glamorous trips to exotic locations (Mauritius and Hong Kong). As it can be seen from Image 6, both fashion couples make regular profile posts featuring them together either in matching outfits or matching poses, and sometimes also utilizing personalized hashtags: \#alinasicarmen by CeusanGrebenisan and \#fabulousmuses by Enciu-Tanase. Furthermore, fashion bloggers share similar features with their partners, giving the impression of actual sisterhood and not just the simulated friendshipsisterhood idea. 
Image 6: from left- published on Instagram by Alina Tanase on April 29th, 2017 and by Carmen Grebenisan on March 2nd, 2017
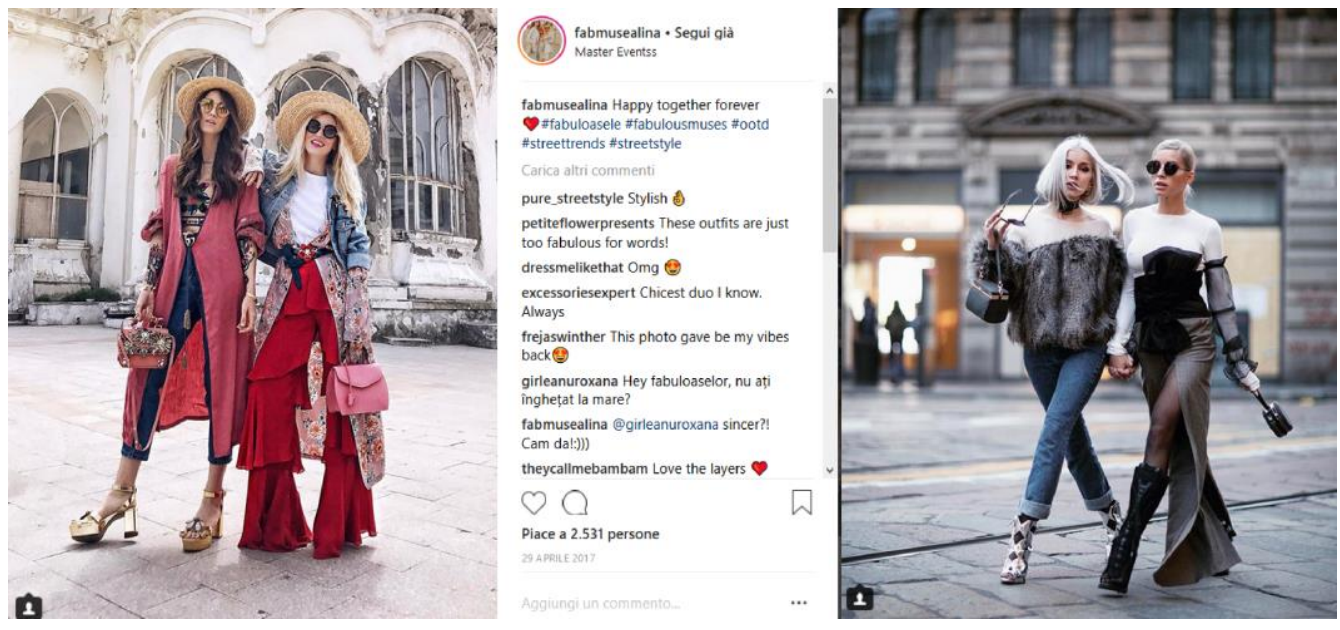

The Enciu-Tanase fashion couple is more professional in term of their choice of imagery; with most of their pictures looking like the result of a meticulous photoshoot, with a combination of sexy pictures featuring them in only a bathrobe or in provocative postures. Nonetheless, they remain behind in terms of popularity when compared to Ceusan-Grebenisan. One reason could be correlated to the fact that their content does not seem genuine through their carefully constructed postings. In line with this view, Enciu and Tanase's Instagram Stories lack the 'silly' aspect that Ceusan or Grebenisan are not afraid to portray. We will explain more in-depth the idea of 'acting silly' in the next part of the article.

It is also interesting to note that the fashion couples display a sort of amorous relationship, with photos in which they are holding hands or almost kissing and captions stating their love for one another, as can be seen in Image 6 and Image 7. This behavior could be considered another marketing technique in light of the advancement of the LGBT movement, as fashion bloggers attempt to expand their audience with lesbian and bisexual females (Rohlinger, 2002, p.72). 
Image 7: from left- published on Instagram by Diana Enciu on March 8th, 2017, Ioana Grama on March 31st, 2017 and Carmen Grebenisan on March 4th, 2017
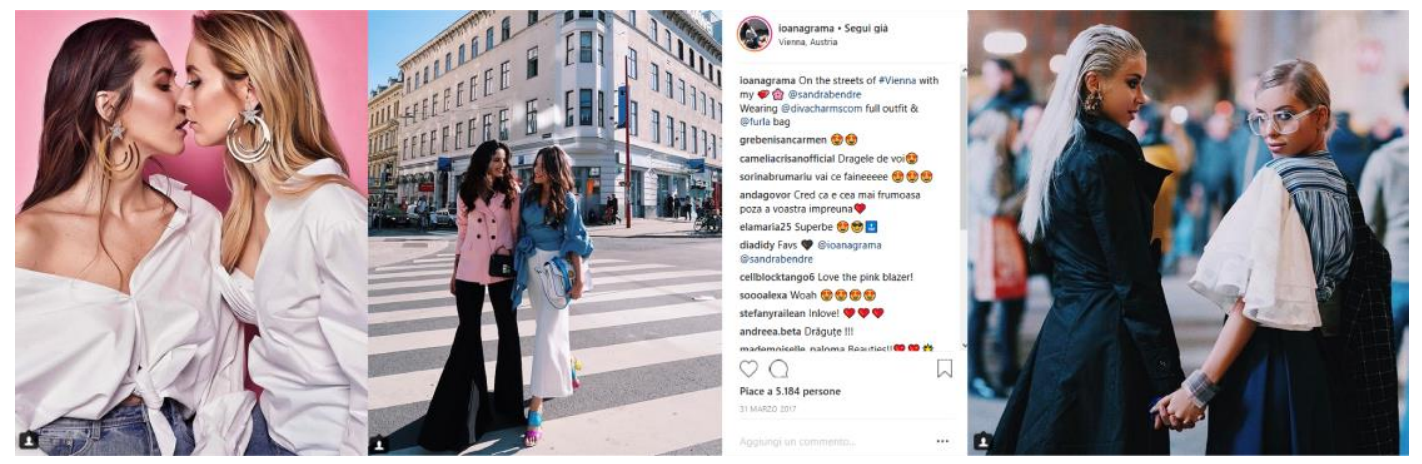

Another major phenomenon we observed is the fact that Romanian fashion bloggers constantly engage with the fashion and digital Romanian community through creative collaborations. An example is Ioana Grama joining Patricia Blaj and H\&Ms project "Style has no size" (an example from the campaign is Image 8), which aimed to demonstrate that Blaj, a 'plus size' body type, is just as fashionable as Grama, a skinny fashion blogger. Through this interaction and co-photoshoot, Grama and Blaj expanded their followers list with one another's (Koughan \& Rushkoff, 2014). Blaj is an alternative culture enthusiast: her screen name is 'weareoutsiders', describing herself as an outcast because she doesn't fit in society's beauty norms. By associating with such a character, Grama, a mainstream fashion blogger, has the potential of gaining new ground and legitimacy in the alternative culture and thus grow her audience.

Image 8: published on Instagram by Ioana Grama on April 10th, 2017
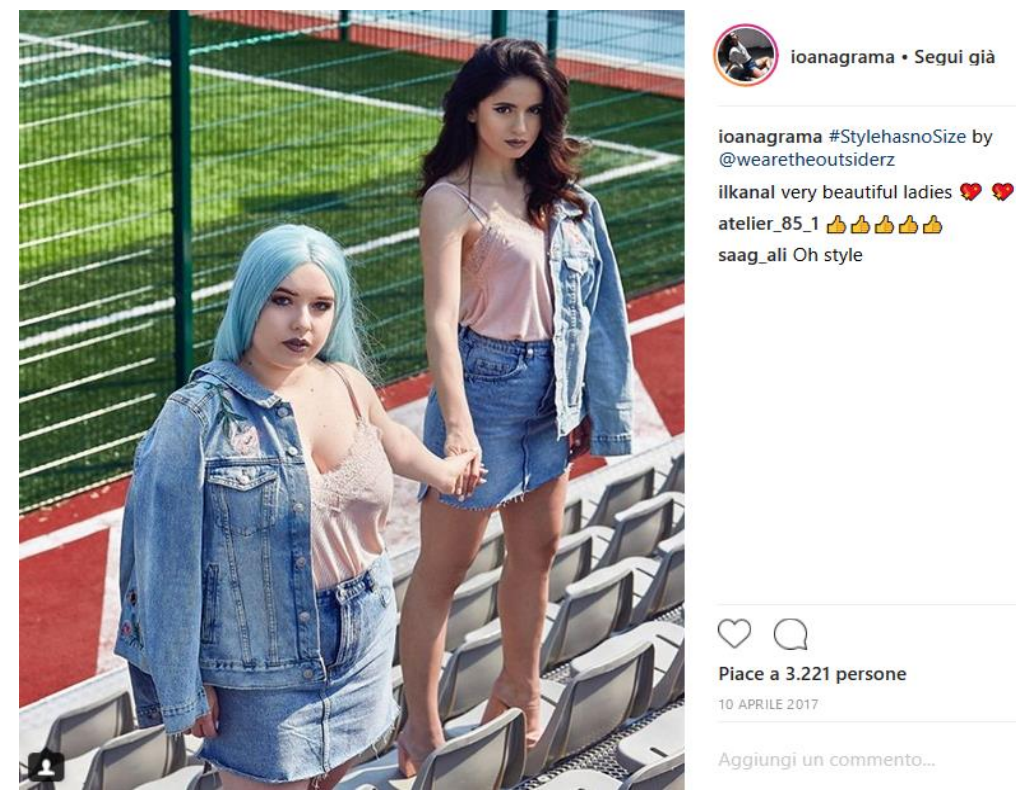

saag_ali Oh style

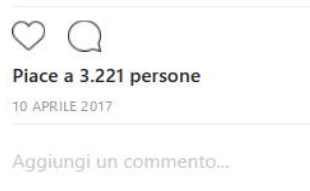


The interest in associating oneself with an alternative, rebellious, niche culture seems to be a trend amongst mainstream Romanian fashion bloggers. Their usage of certain key elements such as a motorbike, leather items, hairstyle choices, or fake tattoos, brings them closer to different subcultures. As can be seen from Images 11, 12 and 13, the trend is popular amongst the majority: Ceusan, Negru, Merca, but also Grebenisan and Grama. Interestingly, the two bloggers lacking alternative elements in their posts (Enciu and Tanase) are also the ones that didn't gain as many followers over the analyzed period. This aspect highlights how fond Romanian audiences are of alternative content.

Image 9: from left- published on Instagram by Sanziana Negru on April 20th, 2017, Alina Ceusan on March 24th, 2017 and Madalina Merca on March 2nd, 2017

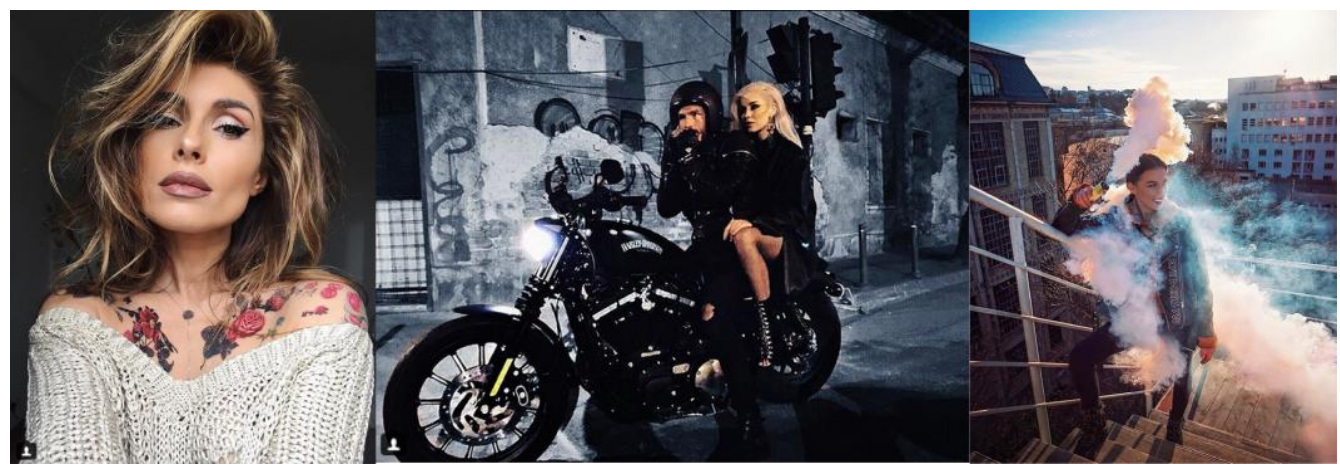

Koughan and Rushkoff noticed that bloggers use one another to build larger communities and to encourage followers to expand their opinion leaders' interests (2014). By tagging each other in photos, fashion bloggers increase each other's visibility, being it a group photo or a mention in the description. Image 10 shows Enciu clustering a lot of tags in the corner of her photo. The tags are not even visible unless the viewer pays close attention to the photo, which means that her usage of tags is particularly relevant for increase of visibility and hypertextuality with other fashion bloggers and brands. 
Image 10: published on Instagram by Diana Enciu on April 18th, 2017
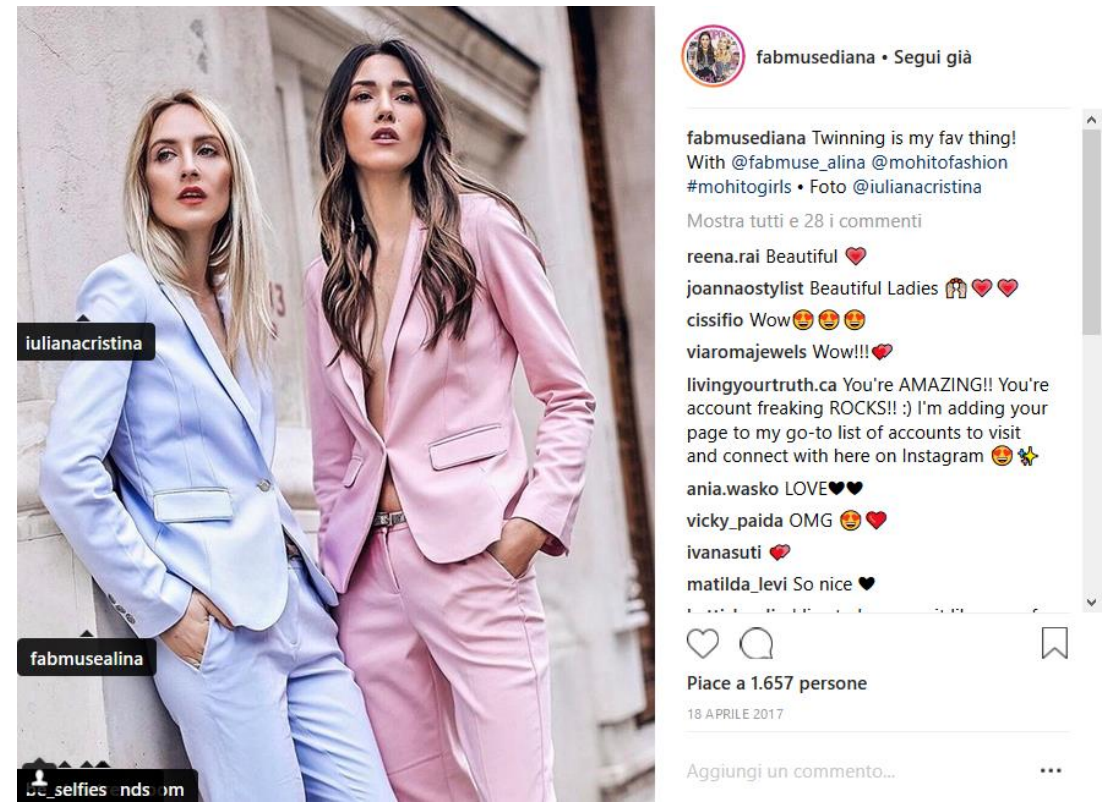

Observation analysis of Instagram Story posts

The following considerations are based on a daily personal observation of around 1000 Story posts published by the seven bloggers that constitute our selected unit of analysis. Romanian fashion bloggers seem to use their Stories to assure their followers that they are ordinary people by acting goofy, showing what they are doing throughout the day in their backstage and interacting in almost real time with their audience (for instance, through comments during 'Live Stories'). Having these moments to discuss and engage with followers is a terrific way to show empathy and strengthen the influencer's trustworthiness as per Marwick's argument that bloggers need to prove 'authenticity' (2013, p.7).

Fashion blogging blends with self-branding, as the individuals behind the persona is using oneself as an entertaining figure and opinion leader for a mass audience (Laurell, 2016, p.522; Marwick, 2013, p.7). What differentiates them from official brands is that they appear as ordinary people. Marwick states that fashion blogs should not aim for perfection, which is associated with corporations and thus distrusted by the audience. The media scholar also believes that a fashion blogger's voice needs to be consistent over time and across channels to maintain the trust of her followers (2013, pp.5-6). Nonetheless, these two affirmations are contradicting one another when considering fashion bloggers' discrepancy between Feed and Story posts.

The most popular bloggers post around 20 Stories every day. Posts can be categorized in four main categories (in alphabetical order): Acting Silly, Behind the Scenes, Edited Photos and Vlogging. Romanian fashion bloggers strengthen their status as 'authentic' content creators through the second type of 
Instagram Story identified - Acting Silly. Grebenisan and Ceusan would do regular Stories in which they fool around, laugh, are inconsistent in their speech and nag each other. Such an example was made on April $14^{\text {th }}$, by Grebenisan, in a Story featuring the two as slightly tipsy after an Easter lunch. The two women were in the back of a car, joking and alluding at their tipsy state. This is not the type of information an official brand would share with their followers.

As part of the Behind the Scenes category, fashion bloggers do not only offer peaks at exclusive brand products or their new projects, but also explain the creative process itself. For instance, on March 23rd, 2017, Madalina Merca's Instagram Story featured her announcing that she finished editing a new vlog which will soon be uploaded on YouTube. On April $25^{\text {th }}$, Grebenisan let her audience know that she was working on a teaser video for a fashion designer. Similarly, Negru and Ceusan often announce on their Instagram Stories their latest vlog, prompting their followers to access it on YouTube. Moreover, there are often posts, both on the Feed and in the Story, featuring the fashion bloggers with professional equipment and taking photos of each other. This hints at the fact that the bloggers are techno-savvy, meaning that they have the capabilities to shoot and edit their own content (in both image and video format), which serves as a further legitimization of their 'authentic' postings, proving to be genuinely creating and sharing their own content. There are exceptions which consist in photos shared from official photoshoots done for brand collaborations, as those photos are shot and edited by hired professionals. Examples of photos from professional shootings, brand collaborations or replicas of the Feed's latest Outfit post are sometimes shared on the Story as well, categorized in our analyses as Edited Photos.

Finally, posts from the Vlogging category refer to the times when the fashion blogger talks directly to her followers about her day, shares her thoughts on a subject or simply journals her day in video format. This usually occurs during driving or simply resting in the car. Instagram Story videos allow for a meaningful recording time of 1 minute (versus Snapchat's 10 seconds for instance), as well as a 'Hand-Free' mode which makes it easier to use when doing other activities (such as driving). Since fashion bloggers are expected to provide a lot of content for their followers, they take advantage of the 'dead' time of driving and use it as an excuse to directly engage and emphasize with their viewers. They can also choose to do a live video, which facilitates multitasking as it records without the need to continually press anything.

The above-mentioned categories describing the posting activity (Feed and Stories) of seven relevant Romanian fashion bloggers confirm the theoretical framework. They act as: 1) opinion leaders and trendsetters; 2) interactive and collaborative personas; and 3) 'authentic' content creators. The most important characteristic is the first one. Indeed, when fashion bloggers share an Outfit, do Brand Promotion, publish a Selfie with the outfit of the day or post pictures displaying Food \& Drinks, Interior design objects or working out at the Gym, they act as opinion leaders and trendsetter, willing to show they master contemporary trends, values and lifestyles.

As a secondary trait, most fashion bloggers appear as interactive and collaborative personas: they have established a long-lasting horizontal creative collaboration with their Fashion Partner (forming fashion couples) with whom they even share business ventures and, from time to time, they also post some Group Pictures, tagging each other in photos. Comparing the average of posts the bloggers make with their Fashion 
Partner or Group Picture Posts (total monthly average of 10.7) with their total monthly average number of posts (48.81) and subtracting the posts that don't feature anyone, such as the ones of Food \& Drinks, Interior Design and Other (16.62), it becomes clear that, similarly to international Instagram fashion bloggers, the Romanian ones prefer having posts featuring only themselves (portrayed by the result of total monthly average of 21.49 posts), thus confirming the celebration of individualism as part of the Instagram culture.

Thirdly, in terms of being 'authentic' content creators, a successful fashion blogger must add her personal style to everything she posts (e.g. personal comments, chats, pros and cons of a product). This direct and apparently honest posting activity conveys a two-fold message: it contributes to reinforce a standardized taste (posture, gesture, etc.), while also establishing intimacy and empathy with the followers, as the Behind the Scenes and the Acting Silly Feed and Story posts revealed. Moreover, the Instagram Story represents a space where the bloggers seem to not pay as much attention to their posts (shown by the small number of posts fitting the Edited Photos category); they can stutter, joke around (Acting Silly posts), speak their mind freely (Vlogging posts), or offer insights about their collaborations (Behind the Scenes posts).

\section{Conclusion and future research steps}

What are then, considering this analysis, the main characteristics that make an 'authentic' fashion blogger? Firstly, in the accelerating fashion environment, fashion bloggers maintain a constant and regular engagement through social media: there is almost no day of rest, with an average of 4.37 Feed posts/day. Their Instagram profiles display a wide variety of categories when it comes to posted photos. As fashion enthusiasts, the predominant category, Outfits, features highly edited photos which emphasize the bloggers' acquired model skills and keep their audiences hooked. They act as opinion leaders connecting the exclusive official fashion culture based on individuality (stylists, models, divas, etc.) with the collective and grassroot Internet culture (based on hashtags, tagging and user generated content). Indeed, they interpret a twofold role: they simultaneously act as 'soloists', mastering mainstream fashion culture (as the assimilation of movement skills shows) and as community members establishing horizontal collaborations - duos - with other fashion bloggers.

In terms of interaction and collaboration, common trends that Romanian fashion bloggers adhere to are having a Fashion Partner or associating themselves with the alternative culture. Drawing from Koughan's research, we found that some of the most famous Romanian fashion bloggers make constant use of tags. Regular collaborations and postings with another fashion blogger aid the growth of both influencers' audiences ${ }^{16}$. Furthermore, some of the fashion bloggers have gone as far as crossing the border of their mainstream fashion tone (understood as the predominant fashion style of their posts) and try to reach more

\footnotetext{
${ }^{16}$ Moreover, tagging other fashion bloggers, as well as establishing frequent and fast interactions with their followers, are both effective strategies to cope with recent Instagram algorithm updates that prioritize top accounts (in terms of followers, comments and Story views), thus confirming the "richer get richer" trend.
} 
niche audiences belonging to alternative subcultures, either by direct association with a well-established member or by including alternative culture elements in their postings, such as the above mentioned amorous relationship endorsing LGBT culture and supporting lesbian imagery. Alternatively, the few bloggers who did not engage in (Diana Enciu and Alina Tanase) gained less new followers over the period of analysis, resulting in the loss of their ranking positions.

Another interesting finding of our research is the importance of transmedia storytelling (i.e. a multi-platform storytelling) among various social media platforms (Jenkins, 2006). Bloggers who worked on being present on multiple SNS, especially by combining Facebook, Instagram and YouTube, earned wider follower numbers on Instagram than those who did not. Vlogging represents a lucrative phenomenon, attracting attention, pushing engagement and generating advertising revenues for the bloggers themselves. We have observed, for instance, bloggers interlacing their vlogging activity from YouTube and Instagram Stories for a greater impact.

Lastly, talking about authenticity, too much professionalism tends to scare followers away, as it brings fashion bloggers closer to a fashion professional and further away from the image of an ordinary individual. Thus, even though they engage in brand collaborations, fashion bloggers assure their 'authenticity' and genuine opinions through the employment of the Instagram Story due to its $24 \mathrm{~h}$ time-boundary. As a result, fashion bloggers on Instagram perform a hyper-mediated authenticity based on sophisticated marketing techniques and apparently informal postings that, far from publishing objective product reviews, mainly reproduces commercialism, thus reinforcing the consumerist society we live in.

The next step of the research will be a wider analysis of the influence between the international fashion sphere and the Romanian fashion bloggers to reveal to what extent they rely on more popular, international fashion bloggers ${ }^{17}$ such as Chiara Ferragni or Micah Gianneli (commonly followed by the Romanian bloggers mentioned in this article). A further step could include collecting 'elicit data' in the form of interviews done through video calls (Salmons, 2016, p.7) with the selected group of fashion bloggers analyzed so far. The aim is to explore how fashion bloggers perceive their role in relation to their followers and to the fashion industry; to what extent they consider themselves professionals; the strategies they adopt to engage with the audience; the tactics they adopt to manage and take advantage of the continuous Instagram algorithm changes; perceived affordances and constraints of Instagram's Feed and Story posts.

\section{References}

Arvidsson, A. (2006). Brands: Meaning and value in media culture. New York: Routledge.

Barthes, R. (1964), Rhétorique de l'image. Communication, 4, pp. 40-51.

Baym, N., \& Senft, T. (2015). What does the selfie say? Investigating a global phenomenon. International Journal of Communication, 9, 1588-1606.

\footnotetext{
${ }^{17}$ The main requirement for international profiles is a majority of English written/spoken posts.
} 
Becker, T. (2016, January 26). How and Why 13-24 Year-Olds Use Instagram. Retrieved March 24, 2017, from https://socialmediaweek.org/blog/2016/01/how-why-13-24-year-olds-use-instagram/

Bolter, J. (2001). Writing Space. New York: Routledge.

Bourdieu, P. (1980). Le Capital Social: Notes Provisoires. Actes de la Recherche en Sciences Sociales, 3(23).

Bruns, A. (2005). Gatewatching. New York: Peter Lang.

Carlson, M. (2007). Blogs and Journalistic Authority. Journalism Studies, 8(2), 264-279.

Cerić, V. (2013). Digital Text: Interactivity and Intertextuality. Online Journal of Art and Design, 1(1), 1731.

Debord, G. (1967). La Société du Spectacle. Paris: Buchet/Chastel.

Gheorghe, G. (2014, April 29). 10 Contemporary Romanian Designers You Should Know. Retrieved July 14, 2018, from https://theculturetrip.com/europe/romania/articles/10-contemporary-romaniandesigners-you-should-know/

Goffman, E. (1959). The Presentation of Self in Everyday Life. Garden City, AT: Doubleday.

Greenwood, S., Perrin, A., \& Duggan, M. (2016, November 11). Social Media Update 2016. Retrieved March 24, 2017, from http://www.pewinternet.org/2016/11/11/social-media-update-2016/

Jenkins, H. (2006). Convergence Culture. New York: New York University Press.

Jenkins, H., Ford, S., \& Green, J. (2013). Spreadable Media: Creating value and meaning in a networked culture. New York: New York University Press.

Katz, E., \& Lazarsfeld, P. F. (1955). Personal Influence. New York, NY, US: Free Press.

Koughan, F., \& Rushkoff, D. (Writers). (2014, February 18). Generation Like [Documentary]. United States: Frontline. Retrieved March 5, 2017, from http://www.pbs.org/wgbh/frontline/film/generation-like/.

Landow, G. P. (2006). Hypertext 3.0: Critical Theory and New Media in an Era of Globalization (3rd ed.). The Johns Hopkins University Press.

Laurell, C. (2014), Commercializing Social Media: A Study of Fashion (Blogo)Spheres. Stockholm University School of Business. Stockholm, Sweden: Doctoral thesis.

Laurell, C. (2016). Fashion spheres - from a systemic to a sphereological perspective of fashion. Fashion Marketing and Management, 20(4), 520-530.

Marwick, A. (2013). They're Really Profound Women, 'They're Entrepreneurs': Conceptions of Authenticity in Fashion Blogging. International Conference on Weblogs and Social Media (ICWSM), 1-8. Retrieved April $30 \quad$ 2017, from http://www.tiara.org/wpcontent/uploads/2018/05/amarwick fashionblogs ICWSM 2013.pdf

Moore, R. (2016, August 23). Snapchat stories vs. Instagram stories: Which Is Best for Your Content: Social Media Examiner. Retrieved April 30, 2017, from http://www.socialmediaexaminer.com/snapchatstories-vs-instagram-stories-which-is-best-for-your-content/

Nahapiet, J., \& Ghoshal, S. (1998). Social capital, intellectual capital and the organizational advantage. Academy of Management Review, 23, 242-266. 
O'Reilly, T. (2005), «What is Web 2.0. Design Patterns and Business Models for the next Generation of Software». Retrieved April 30, 2017, from www.oreillynet.com

Peraica, A. (2017). Culture of the selfie: self-representation in contemporary visual culture. Amsterdam: Institute of Network Cultures.

Pham, M-H. T. (2011). Blog ambition: Fashion, feelings, and the political economy of the digital raced body. Camera Obscura, 26(1 76), 1-37.

Ramos-Serrano, M., \& Martínez-García, A. (2016). Personal style bloggers: The most popular visual composition principles and themes on instagram. Observatorio (OBS*) Journal, 10(2), 89-109.

Rocamora, A. (2012). Hypertextuality and Remediation In The Fashion Media. Journalism Practice, 6(1), 92106. DOI: $10.1080 / 17512786.2011 .622914$.

Rogers, E. (1995). Diffusion of Innovations. USA, New York: The Free Press.

Rohlinger, D. (2002). Eroticizing men: Cultural influences on advertising and male objectification. Sex Roles: A Journal of Research, 46(3-4), 61-74.

Salmons, J. (2016). Doing Qualitative Research Online. Los Angeles: Sage.

Sarasohn-Kahn, J. (2016, January 22). We Are All Foodies Now. Retrieved March 24, 2017 from https://www.huffingtonpost.com/jane-sarasohnkahn/we-are-all-foodiesnow b 9053510. html?guccounter $=1$

Schaefer, M. (2014). Social media explained: untangling the world's most misunderstood business trend. United States: Schaefer Marketing Solutions.

Shively K. (2015, December 8). The 2015 Instagram Industry Report. Retrieved March 24, 2017, from http://simplymeasured.com/blog/the-2015-instagram-industryreport/\#sm.0001j8yicjtxufaupsi2oxnx4hnqg

Statista (2017, December). Leading brands ranked by number of Instagram followers as of December 2017 [Statistics] Retrieved March 23, 2018, from https://www.statista.com/statistics/253710/leadingbrands-ranked-by-number-of-instagram-followers/

Tomiuc, A., \& Stan, O. (2015). The Fashion Blogosphere in Romania. Fashionscape And Fashion Bloggers. Postmodern Openings, 6(1), 161-174.

Tomlinson, J. (2007). The Culture of Speed. London: Sage.

Wiedmann, K-P., Henning, N., \& Langner, S. (2010). Spreading the Word of Fashion: Identifying Social Influencers in Fashion Marketing. Journal of Global Fashion Marketing: Bridging Fashion and Marketing, 1(3), 142-153. 